\title{
Analysis of the Fracture Surfaces of New Development Insulated Iron Powder Compounds
}

\author{
R. BidulskÝ ${ }^{a}$, J. Bidulská ${ }^{a}$, T. KVAČKAJ ${ }^{a, *}$, M. ACtis Grande ${ }^{b}$ \\ ${ }^{a}$ Faculty of Metallurgy, Technical University of Košice, Letná 9, 04200 Košice, Slovakia \\ ${ }^{b}$ Department of Applied Science and Technology, Politecnico di Torino, V. T. Michel 5, 15100 Alessandria, Italy

\begin{abstract}
Goal of the present paper is the analysis of the fracture surfaces of an Insulated Iron Powder Compound (IIPC) with different additions of aluminium alloy $(0.25,0.5$ and $0.75 \mathrm{wt} . \%)$, in order to improve the mechanical properties, evaluated as the transverse rupture strength (TRS) with sufficient magnetic properties (mainly represented by the iron loss and coercivity force). Investigation of microstructure and porosity development concluded that improvements in bending strength and impact values require the reduction of surface oxides during the heat treatment, in order to get a proper load bearing area between the adjacent particles.
\end{abstract}

DOI: $10.12693 /$ APhysPolA.126.154

PACS: $75.50 .-\mathrm{y}, 81.20 . \mathrm{Ev}, 81.40 . \mathrm{Np}$

\section{Introduction}

The ideal soft magnetic material, with respect to IIPC (Iron Insulated Powder Compound), is an isotropic media with very high magnetic permeability, low coercivity and high saturation induction. In addition, the material could be easily shaped into 3D structures in order to fully take advantage of the material's isotropic nature [1-5].

Due to the fact, as underlined in the past activity [6-9], that a maximum temperature of about $500{ }^{\circ} \mathrm{C}$ is compatible with the conservation of good magnetic properties of IIPC, the attention has been devoted to select a material able to introduce mechanical advantages under heat treatment at the reported temperature. As a consequence, the attention has been addressed to the aluminium, which at $500{ }^{\circ} \mathrm{C}$ presents a sort of pre-sintering behaviour with the possibility of a fluid migration around the IIPC grains, and good rigidity after the cooling process. Different powders have therefore been mixed, the soft magnetic powder (IIPC) and an $\mathrm{Al}-\mathrm{Mg}-\mathrm{Si}-\mathrm{Cu}$ alloy (as the additional element), this latter responsible for the more homogeneous microstructure and as a better plastical ability agent than matrix powder one. Despite the densification phenomena provided by the aluminium alloy $[10,11]$, some additional research, focused on the densification behaviour is needed. The more details about the role of aluminium based alloy in iron based SMC on magnetic materials, as well as the comparison of the properties of investigated materials with original SMC is presented in [12].

\section{Experimental procedures}

The IIPC material (commercial Somaloy 1P 700 powder, Höganäs) has been blended with different amounts of aluminium alloy (commercial ready-to-press aluminium based powder Alumix 321: Al - 0.95 wt.\%, Mg -

\footnotetext{
*corresponding author; e-mail: tibor.kvackaj@tuke.sk
}

0.49 wt. $\%, \mathrm{Si}-0.21$ wt. $\%, \mathrm{Cu}-0.07$ wt. $\%, \mathrm{Fe}-1.6$ wt. $\%$, lubricant, Ecka Granules). The investigated systems are given in Table I.

The investigated systems.

TABLE I

\begin{tabular}{c|c}
\hline \hline System & Chemical compositions \\
\hline 1 & IIPC $+0.25 \%$ Alumix 321 \\
\hline 2 & IIPC $+0.5 \%$ Alumix 321 \\
\hline 3 & IIPC $+0.75 \%$ Alumix 321
\end{tabular}

Powder mixtures were homogenized using a laboratory Turbula mixer for $20 \mathrm{~min}$. Specimens with a different green density, obtained using a $2000 \mathrm{kN}$ hydraulic press, in a disc-shaped mould $(\Phi 40 \mathrm{~mm})$ and unnotched impact energy $55 \times 10 \times 10 \mathrm{~mm}^{3}$ specimens applying a pressure in the range $200,300,400,500,600$ and $700 \mathrm{MPa}$. Thermal treatments in air at the maximum temperature of $500^{\circ}$ $\mathrm{C}$ for $30 \mathrm{~min}$ were carried out on the evaluated systems.

The three-point bending (transverse rupture strength TRS) test is based on the deformation of the specimen by bending with slow force until the moment when material failure occurs in the area of tension/stress.

Fracture surfaces were investigated by means of SEM JEOL 7000F. Densities were evaluated using the water displacement method (Archimede's principle), according to the ASTM B962 - 08 standard.

\section{Results and discussion}

Strength properties, evaluated in terms of TRS values, are reported in the following Table II.

TABLE II

Strength properties represent by TRS values in $\mathrm{MPa}$.

\begin{tabular}{c|c|c|c|c|c|c}
\hline \hline $\mathrm{p}(\mathrm{MPa})$ & 200 & 300 & 400 & 500 & 600 & 700 \\
\hline 1 & 25.25 & 43.26 & 42.64 & 27.75 & 20.62 & 19.35 \\
\hline 2 & 34.76 & 43.56 & 39.88 & 26.98 & 20.24 & 19.33 \\
\hline 3 & 37.74 & 44.77 & 40.79 & 21.60 & 18.08 & 16.56
\end{tabular}


It is evident that, when applying compacting pressures of $500 \mathrm{MPa}$ or higher, a break point occurs in the measured mechanical properties, presumably due to the spring back effect deriving from the presence of $\mathrm{Al}$ based powders.

To further study the heat treatment response of investigated systems, the evaluation of fracture surfaces was performed. The main aim of the heat treatment process is to develop inter-particle bonds, homogeneous distribution of aluminium alloying elements, and a reduction in porosity. As shown in Fig. 1-3, a low level of sinter necks was reached after heat treatment. There was no evidence of major plastic strains at the inter-particle necks. In addition, well-defined insulated surfaces were present in the systems close to the areas where secondary porosity was present.

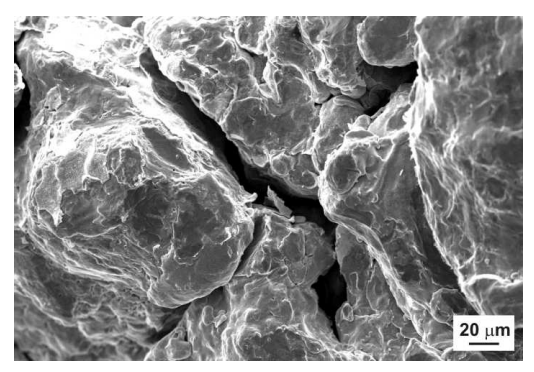

Fig. 1. Fracture surface of system 1.

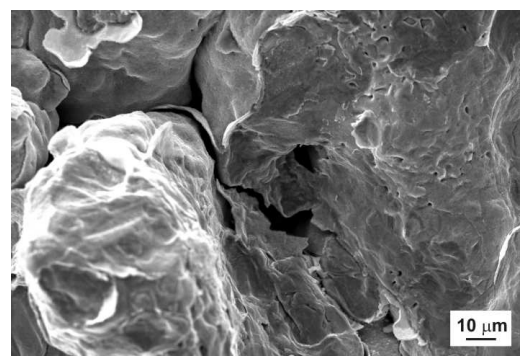

Fig. 2. Fracture surface of system 2.

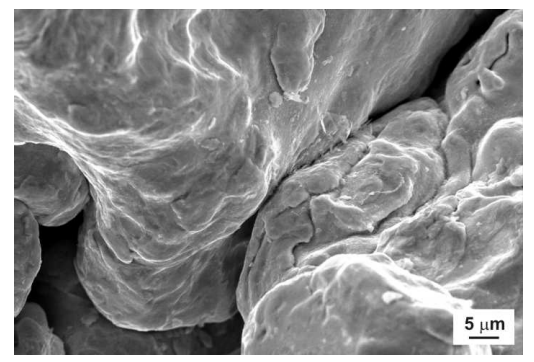

Fig. 3. Fracture surface of system 3 .

The fracture analysis of investigated systems puts into evidence the breaking of inter-particle neck connections. Heat treatment (at the temperature of $500^{\circ} \mathrm{C}$ ) contributes to the early stages of inter-particle neck devel- opments. The chosen aluminium alloy presents a sort of pre-sintering behaviour at $500^{\circ} \mathrm{C}$, with the possibility of mass-transport processes around the IIPC, whereas the applied air heat treatment, aims at providing an increase in the mechanical behaviour of the material, with a final good rigidity after the cooling process. Fracture surfaces and TRS values show that, at $500 \mathrm{MPa}$, the strength and the area related to the inter-particle necks can be correlated to the occasional broken insulated point-to-point surfaces that hinder the development of inter-particles necks.

\section{Conclusions}

The goal of the present paper is to study the possible improvements of mechanical properties of IIPC parts by means of the introduction of an aluminium alloy into the powder mix. The strength properties of new investigated systems depend on the occasional broken insulated point-to-point surfaces, hindering the development of inter-particles necks.

\section{Acknowledgments}

This work was realized within the frame of the Operational Program Research and Development: "The centre of competence for industrial research and development in the field of light metals and composites", project code ITMS: 26220220154 and financially supported by a European Regional Development Fund.

\section{References}

[1] H. Shokrollahi, K. Janghorban, J. Mater. Process. Technol. 189, 1 (2007).

[2] J. Füzer, P. Kollár, D. Olekšáková, S. Roth, J. Alloy. Compd. 483, 557 (2009).

[3] J. Füzer, J. Bednarčik, P. Kollár, Acta Phys. Slovaca 56, 119 (2006).

[4] D. Olekšáková, J. Füzer, P. Kollár, S. Roth, J. Magn. Magn. Mater. 333, 18 (2013).

[5] C. Oikonomou, E. Hryha, L. Nyborg, Surf. Interface Anal. 44, 1166 (2012).

[6] R. Bidulský, M. Actis Grande, L. Ferraris, P. Ferraris, J. Bidulská, Acta Phys. Pol. A 118, 802 (2010).

[7] I.P. Gilbert, V. Moorthy, S.J. Bull, J.T. Evans, A.G. Jack, J. Magn. Magn. Mater. 242-245, 232 (2002).

[8] J. Bidulská, T. Kvačkaj, R. Bidulský, M. Actis Grande, L. Ferraris, Acta Phys. Pol. A 118, 800 (2010).

[9] R. Bidulský, M. Actis Grande, L. Ferraris, J. Bidulská, J. Optoelectron. Adv. Mater. 12, 1356 (2010).

[10] J. Bidulská, T. Kvačkaj, R. Bidulský, M. Actis Grande, L. Dobrzynska, J. Dutkiewicz, Chem. Listy 105, s471 (2011).

[11] J. Bidulská, R. Kočiško, R. Bidulský, M.A. Grande, T. Donič, M. Martikán, Acta Metall. Slovaca 16, 4 (2010).

[12] M. Actis Grande, R. Bidulsky, A. Cavagnino, L. Ferraris, P. Ferraris, IEEE Trans. Ind. Appl. 48, 1335 (2012). 